\title{
IMPRESSORA DE BAIXO CUSTO DESENVOLVIDA A PARTIR DE SISTEMA AUTOMOTIVO DE INJEÇÃO ELETRÔNICA PARA FABRICAÇÃO DE FILMES FINOS ORGÂNICOS
}

Adriana Diniz Barbosa ' Sávio Augusto Lopes da Silva ${ }^{2}$ Robson Nunes Dal Col ${ }^{3}$ Rodrigo Fernando Bianchi ${ }^{4}$

\section{Resumo}

Neste trabalho, é apresentado o desenvolvimento de um novo equipamento para fabricação de filmes finos orgânicos, baseado na tecnologia automotiva de injeção eletrônica. Tal sistema apresenta, dentre as vantagens de disponibilidade comercial e baixo custo, baixas taxas de corrosão química e de problemas de entupimento dos bicos injetores, bem como o controle de taxas de temperatura de deposição. Portanto, apresenta versatilidade para utilização de diversas soluções orgânicas usadas em microeletrônica e eletrônica orgânica, tais como Fotoresistes e polímeros semicondutivos, como o poli(etileno-dioxitiofeno) - PEDOT. Ensaios obtidos com esses materiais mostram que o desempenho do sistema proposto depende de parâmetros como frequência da válvula injetora, diâmetro do orifício ejetor, pressão aplicada na solução impressa e das características da superfície dos substratos, que influenciam diretamente na qualidade dos filmes obtidos.

Palavras-chave: Polímeros; Filme fino; Injeção eletrônica; Controle.

\section{LOW-COST PRINTER DEVELOPED FROM ELECTRONIC INJECTION AUTOMOTIVE SYSTEMS TO MANUFACTURING ORGANIC THIN FILMS}

\begin{abstract}
This paper presents the development of a new equipment for manufacturing organic thin-films based on the technology of electronic fuel injection. This system presents, among the advantages of commercial availability and low cost, low rates of chemical corrosion and problems of nozzle clogging, as well as a temperature rate control system for material deposition. Thus, the developed equipment presents the versatility of using several organic solutions, such as Photoresistes and semiconducting polymers, for microelectronic and organic electronics, such as polyethylenedioxythiophene - PEDOT. Tests obtained with these materials show that system performance depends of parameters such as frequency of the injector valve, ejector orifice diameter, pressure applied in the printed solution and the substrates surface characteristics that influence directly in the quality of films obtained.
\end{abstract}

Key words: Polymer; Thin film; Electronic injection; Control.

\footnotetext{
' Eng. Controle e Automação, M.Sc., Engenharia de Materiais Redemat/UFOP, Rua 4 de Outubro, n. 95, Vila Maquiné, Cep 35420-000, Mariana, MG, Brasil. E-mail: adrianadinizbarbosa@gmail.com

${ }^{2}$ Eng. Eletricista, M.Sc., D.Sc., Prof. Adjunto do Dep. Eng. de Controle e Automação e Técnicas Fundamentais/Escola de Minas/UFOP,

Decat/UFOP - Campus Morro do Cruzeiro s/n, Cep 35400-000, Ouro Preto, MG, Brasil. E-mail: savio@decat.em.ufop.br

${ }^{3}$ Eng. Metalúrgico, M.Sc. Em.a de Materiais, Redemat/UFOP, Av. Luiz Xavier da Costa, 39, Sacramento, Cep 354I0-000,

Cachoeira do Campo, MG, Brasil.E-mail: nunesdalcol@yahoo.com.br

${ }^{4}$ Físico, M.Sc., Doutor em Ciências e Engenharia de Materiais, Prof. Adjunto do Dep. de Física Instituto de Ciências Exatas e Biológicas/UFOP,

Defis/UFOP - Campus Morro do Cruzeiro s/n, Cep 35400-000, Ouro Preto, MG, Brasil. E-mail: bianchi@iceb.ufop.br
} 


\section{INTRODUÇÃO}

Lançada em 2004, a Política Industrial, Tecnológica e de Comércio Exterior (PITCE) do Governo Federal elegeu as áreas de semicondutores, software, bens de capital, fármacos e medicamentos como estratégias para a retomada do crescimento econômico sustentável do País e, consequentemente, da superação dos desequilíbrios internos e externos enfrentados pela economia brasileira nas últimas décadas.(1) Em especial ao que tange à área de semicondutores, tal política é de grande importância para o fortalecimento de uma indústria de base tecnológica e para composição da cadeia produtiva de dispositivos eletroeletrônicos no País, até o momento, assolada pela falta de políticas coordenadas entre os setores produtivos, governo e academia. Nesse contexto, a inserção das indústrias brasileiras na área de semicondutores visa tornar o Brasil competitivo num mercado mundial estimado em US\$ 220 bilhões/ano, com taxas anuais de crescimento da ordem de $13 \%$, dominado, principalmente, por países asiáticos e pelos Estados Unidos da América. (2) Para compor esse quadro, o Centro de Gestão e Estudos Estratégicos do Ministério de Ciência e Tecnologia (CGEE-MCT) elaborou um estudo sobre o mapa atual dos semicondutores orgânicos( ${ }^{(3)}$ no País, cujos resultados apontam a oportunidade de desenvolvimento desses dispositivos como uma ação estratégica para o crescimento industrial do Brasil. Dessa forma, o domínio dessa área de nanotecnologia, ou de eletrônica orgânica, abre perspectivas para inovações que vão desde o desenvolvimento de equipamentos de impressão de filmes finos orgânicos até a fabricação de dispositivos orgânicos flexíveis de alto desempenho. Contudo, no mundo há poucas empresas fabricantes de equipamentos de impressão de materiais orgânicos, o que torna $\circ$ custo desses equipamentos ainda elevado (de US\$90 mil a dezenas de milhares de dólares ${ }^{(4,5)}$ ), e, portanto, de difícil aquisição desses equipamentos por grupos de pesquisas nacionais para fins de pesquisa fundamental. Dentro desse contexto, o desenvolvimento de novos equipamentos é uma oportunidade única de atrelar conhecimento científico a uma área de ciência básica e aplicada cuja carência de novos sistemas de impressão de baixo custo é evidente. Este trabalho apresenta $\circ$ desenvolvimento inédito de um equipamento de impressão para fabricação de filmes orgânicos cuja plataforma mecânica baseia-se no princípio de operação de Sistemas automotivos de Injeção Eletrônica (SiE). Tal sistema, denominado nesse trabalho de Sistema automotivo de Injeção Eletrônica de Materiais Orgânicos (SiEO), apresenta, dentre as vantagens de disponibilidade comercial e baixo custo $(<R \$ 10.000)$, baixas taxas de corrosão química e de entupimento, controle de taxas de temperatura de deposição e, portanto, versatilidade para aplicação de uma ampla gama de soluções orgânicas.

\section{MATERIAIS E MÉTODOS}

A metodologia aplicada nesse trabalho é dividida em duas etapas: a) escolha dos polímeros para fabricação de filmes; e b) projeto e desenvolvimento do equipamento de injeção. Nesse contexto, o polímero utilizado inicialmente para preparação da solução de injeção foi o poli(etileno-dioxitiofeno) (PEDOT), que é um polímero condutor de fácil preparação, baixo custo e bastante utilizado como camada transportadora de cargas em dispositivos emissores de luz poliméricos, ${ }^{(6)}$ bem como Fotoresistes comerciais, AZ-2400 e AZ-I I IS, que são utilizados amplamente na área de microeletrônica. Também foram realizados ensaios com tinta azul comercial para testes prévios do equipamento. Finalmente, o projeto do equipamento de impressão foi baseado na mecânica e na eletrônica disponíveis para Sistemas de Injeção Eletrônica automotiva (SiE). Empregou-se uma válvula de injeção eletrônica, como instrumento de "aspersão" das soluções químicas, devido a sua resistência a ambientes hostis. Essa aplicação foi necessária porque a válvula de injeção desses sistemas é inerte aos solventes orgânicos usualmente utilizados na fabricação de filmes poliméricos, como $\mathrm{N}$-metil-2-pirrolidona (NMP), o clorofórmio e o tolueno. Essa válvula tem a função de pulverizar o combustível em automóveis e, no caso deste trabalho, de pulverizar as soluções orgânicas de forma similar às condições encontradas em impressoras a jato de tinta comerciais.

A deposição das soluções foi realizada por um injetor apropriado (GMFlex) a uma pressão de I,0 bar. O injetor consiste de um corpo de uma válvula de aço inoxidável que contém uma bobina e uma válvula agulha. Nesse caso, quando a corrente no solenóide é nula, a válvula é comprimida de encontro ao seu assento por uma mola helicoidal. Na presença de um fluxo de corrente a válvula, por sua vez, é levantada permitindo assim a injeção da solução através de uma placa de orifício. A quantidade de solução injetada é determinada pela duração de um pulso elétrico. ${ }^{(7)}$ A Figura I mostra um esquema da estrutura interna da válvula injetora. ${ }^{(8)}$

Não obstante à estrutura física e a resistência à corrosão da válvula injetora (Figura la), que são condições necessárias para aspersão das soluções poliméricas, destaca-se ainda que essa válvula é caracterizada pela precisão, confiabilidade, versatilidade e baixo consumo de energia. Assim, a quantidade de solução injetada é facilmente dosada pela unidade de comando pelo tempo de abertura das válvulas de injeção, também conhecido como tempo de injeção." A Figura 2 mostra detalhes da válvula injetora. Já na Figura 2a observa-se o orifício de entrada da solução orgânica, enquanto as Figuras $2 b, 2$ c e 2d mostram, respectivamente, a placa de orifício da válvula injetora

* PANAMBI, L. F. P. Injeção eletrônica. Itabira, 2002. [Material de consulta interna de oficina mecânica]. 

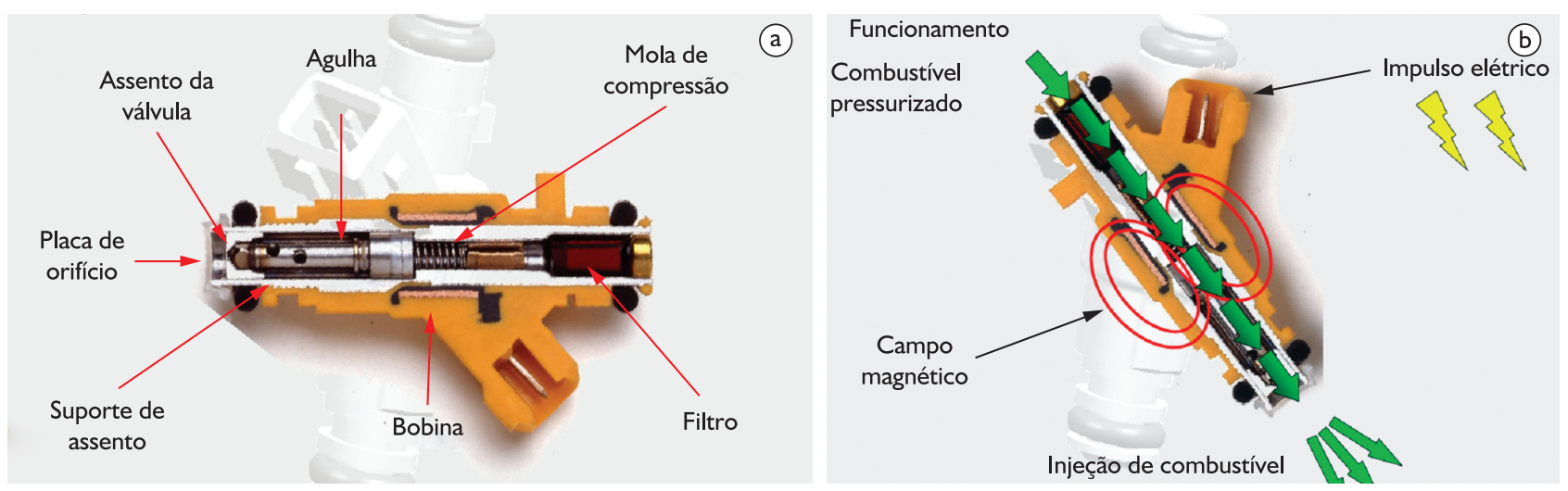

Figura I. Esquema da válvula injetora EV6 utilizada em automóveis quanto a sua: a) estrutura interna; e b) funcionamento básico. ${ }^{(8)}$
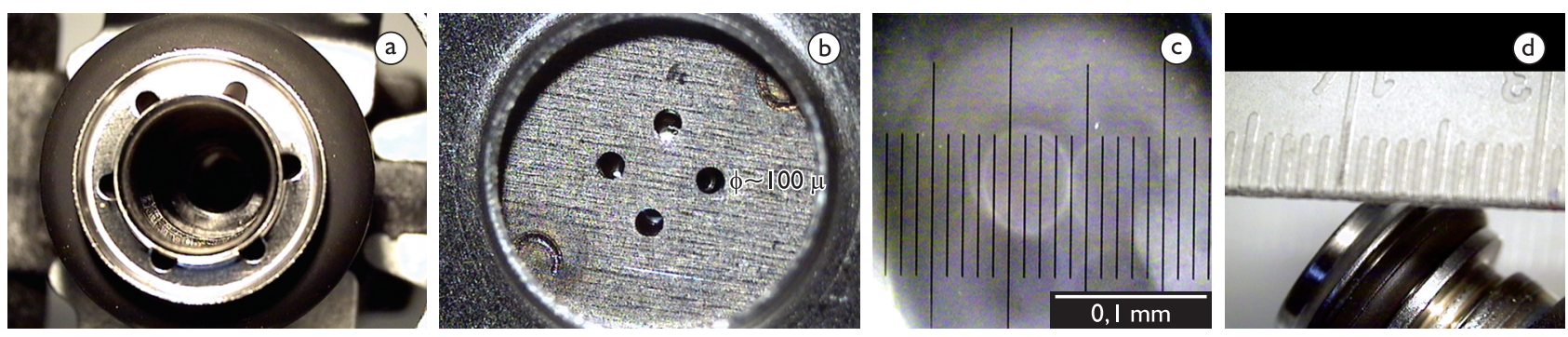

Figura 2. Microscopia da válvula injetora: a) Orifício de entrada da solução orgânica 6,5X; b) Placa de orifício (saída da solução) com quatro furos micropuncionados cujos diâmetros são de $(60 \pm 5) \mu \mathrm{m}, 25 X$; c) Nuzzels ampliados em 50X; e d) Proporção de tamanho da válvula em centímetros. Redução de 6X.

caracterizada por quatro furos micro-puncionados cujo diâmetro médio é igual $(60 \pm 5) \mu \mathrm{m}$, o diâmetro de um dos Nuzzels da válvula injetora e a proporção dessa válvula em relação a um instrumento de medida em centímetros.

Para um melhor desenvolvimento e aperfeiçoamento do equipamento de fabricação de filmes poliméricos foram estudadas as características dos SiEs, tais como, frequência da válvula, temperatura e tensão de trabalho, vazão e corrente. A válvula injetora foi testada inicialmente com tintas comerciais adequadas para análise de sua dispersão. Já para o controle dessa válvula foi utilizada a modulação por tamanho de pulso (PWM - Pulse-Width Modulation), de acordo com o circuito apresentado na Figura 3. Esse circuito engloba a modulação de sua razão cíclica para transportar qualquer informação sobre um canal de comunicação e controlar o valor da alimentação entregue à carga. A PWM utilizada suporta a frequência máxima de $100 \mathrm{kHz}$ e realiza o controle da abertura e fechamento da válvula por meio de variações no valor dessa frequência. $O$ tempo de abertura da válvula injetora, $T[I]$, pode ser regulado de forma independente do tempo de fechamento, $T[0]$, o que permite o controle da ejeção das soluções.

De forma bastante simplificada, a Figura 4 mostra o esquema do aparato experimental usado para impressão das soluções, denominado de Sistema de Injeção Eletrônica de materiais Orgânicos (SiEO). Nesse esquema, uma bomba garante a pressão no compartimento da solução polimérica acoplado à válvula injetora controlada eletronicamente via circuito PWM (Figura 5). As soluções são direcionadas a um substrato colocado sobre uma mesa controladora em X (eixo horizontal), para posterior fabricação dos filmes em regiões pré-definidas. Um pequeno motor foi utilizado para fazer a movimentação do substrato no eixo $X$, uma vez que a válvula injetora permanece imóvel durante todos os ensaios. Destaca-se, ainda, que no equipamento desenvolvido foi utilizado um eixo de movimentação vertical (eixo Z) cuja distância da válvula ao substrato foi controlada manualmente. Foram realizados diferentes ensaios variando-se a distância entre o substrato e a válvula injetora, bem como o tempo de abertura e de fechamento da válvula. $\mathrm{O}$ controle foi realizado manualmente, por meio de botóes liga/desliga, que permite $o$ ajuste dos parâmetros de entrada para controle da ejeção das soluções. A Figura 5 mostra fotos do aparato desenvolvido. Nesta Figura observa-se uma seringa (Figura 5a) à qual foi adaptada a válvula injetora para servir como "armazenamento" da tinta a ser ejetada sobre um dado substrato (papel, poliestireno ou vidro) com dimensões de $(5 \times 5) \mathrm{cm}^{2}$. A válvula injetora foi posicionada a um ângulo cujo encaixe de apoio se encontrava perpendicular ao plano do substrato (Figura 5b). Utilizou-se ainda um motor dc para atuar na movimentação do substrato (eixo $X$ ) durante a ejeção da solução. Foi usada uma fonte dc ajustável para controlar a velocidade de movimentação 


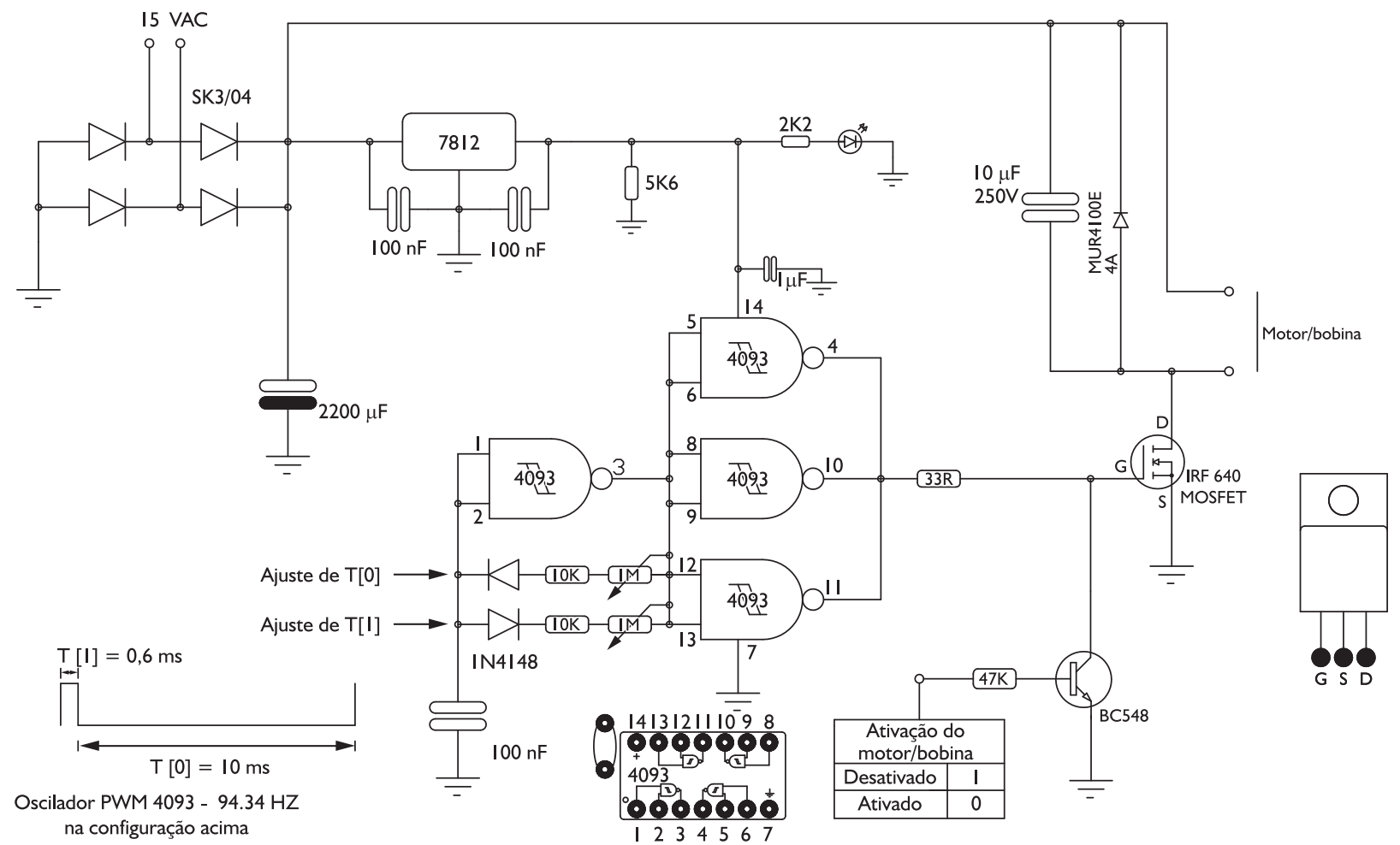

Figura 3. Modulação por largura de pulso (PWM) - circuito oscilador, usado para o controle da frequência de ejeção das soluções orgânicas depositadas.

do substrato simulando, assim, uma mesa controlada em "X". Por meio do circuito PWM foi realizado o controle dos tempos de abertura e fechamento da válvula mantendo-se, para tanto, T[I] em 2 ms e T[0] em 20 ms.

A natureza das interfaces substrato/polímero é de fundamental importância para o estudo das propriedades ópticas e/ou elétricas dos polímeros e de seus dispositivos eletrônicos. Desse modo, a limpeza dos substratos deve ser realizada de modo rigoroso e criterioso antes da deposição dos filmes poliméricos. Em um primeiro momento, os ensaios com Fotoresistes foram realizados em lâminas sem tratamento prévio (in natura). Já em um segundo momento, as lâminas de vidro foram tratadas pelo método $R C A^{(9)}$ de hidrofilização (limpeza de substrato). Nesse método, os substratos passam inicialmente por um banho composto de hidróxido de amônio $\left(\mathrm{NH}_{4} \mathrm{OH}\right)$, peróxido de hidrogênio $\left(\mathrm{H}_{2} \mathrm{O}_{2}\right)$ e água pura a $75^{\circ} \mathrm{C}$ durante 10 minutos; em seguida, são lavadas com água pura abundante e, posteriormente, banhadas em uma solução de ácido clorídrico $(\mathrm{HCl}), \mathrm{H}_{2} \mathrm{O}_{2}$ e água pura a $70^{\circ} \mathrm{C}$ durante 15 minutos. Finalmente, as lâminas são lavadas com água pura abundante, imersas em acetona aquecida e, então, em álcool isopropílico em ebulição e secas com gás de nitrogênio. Os ensaios realizados com os Fotoresistes sobre substratos de vidro in natura visam analisar o comportamento do substrato, papel ou poliestireno transparente, quanto a seu volume e forma, determinando, assim, a hidrofobici-

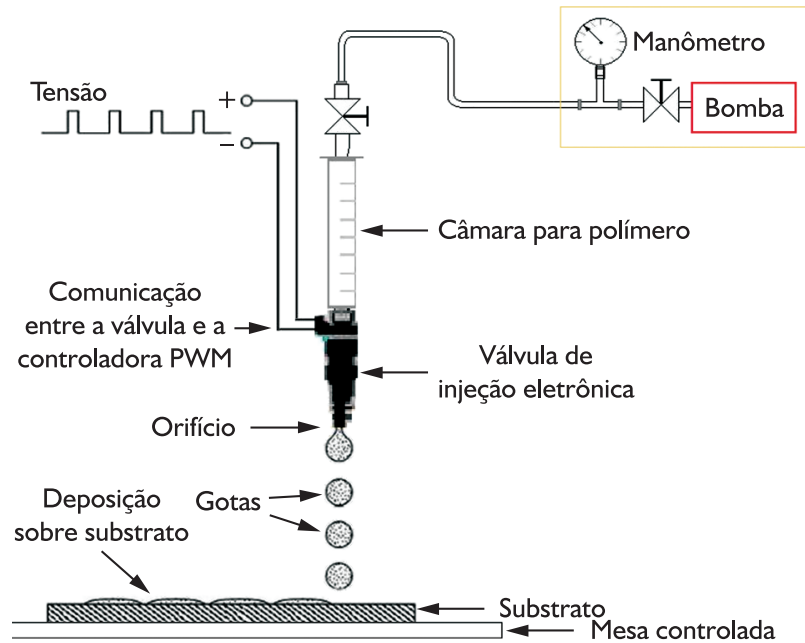

Figura 4. Esquema do princípio de funcionamento de uma impressora denominada de Sistema de Injeção Eletrônica de materiais Orgânicos (SiEO) para recobrimento uniforme de polímeros em substratos planos.

dade do substrato em relação à solução. Lotes de lâminas (substrato) ainda foram expostos à luz ultravioleta (UV) durante 20 minutos, para limpeza e alterações da hidrofobicidade do substrato.

Para otimizar o funcionamento dos $\mathrm{SiEO}$, e assim minimizar os parâmetros de controle desse sistema, foram mantidos constantes e iguais a $2,0 \mathrm{~cm}, 20 \mathrm{~cm} / \mathrm{s}$ e $7,5 \mathrm{~cm}$ de $\mathrm{H}_{2} \mathrm{O}$ à distância (d) substrato-válvula de injeção, velo- 

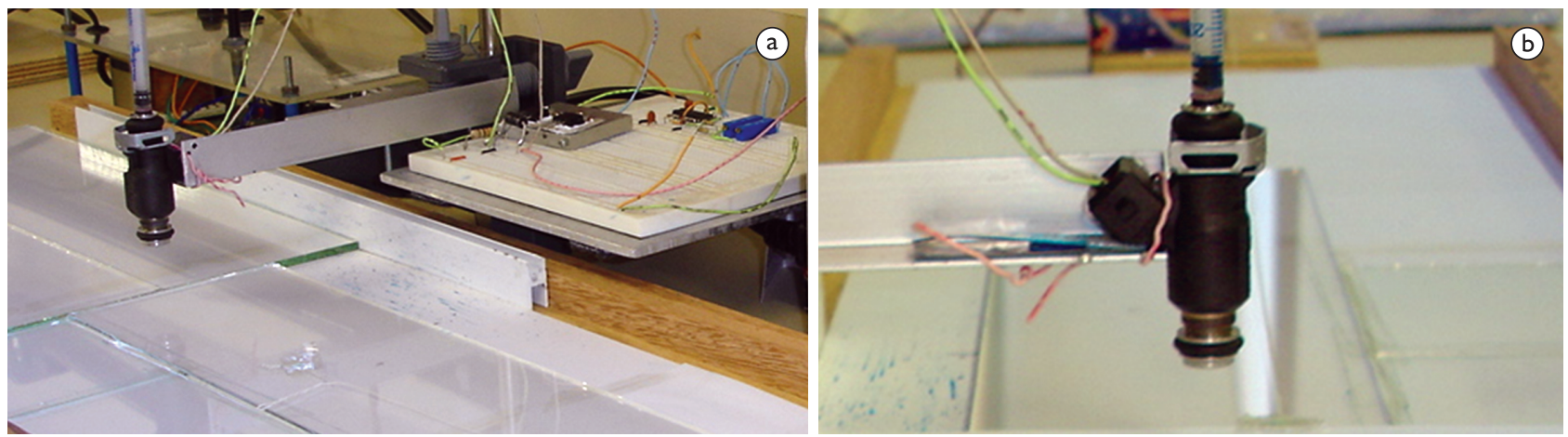

Figura 5. Fotos do aparato utilizado na realização dos ensaios de ejeção: a) sistema completo; e b) funcionamento da válvula de injeção eletrônica automotiva em relação ao substrato.

cidade $(v)$ de movimentação de substrato e à pressão $(P)$ sobre o êmbolo da seringa, respectivamente. Tais parâmetros, otimizados em relação à formação de gotas, foram obtidos por meio do uso de soluções de tinta azul, PEDOT e Fotoresistes (AZ-2400 e AZ-I I IS) cujos resultados de deposição são apresentados nas Figuras 6, 7 e 8a, respectivamente. A Tabela I apresenta parâmetros aplicados em diferentes valores de distância e pressão atmosférica para análise da característica geométrica e volumétrica dos filmes de Fotoresistes depositado. Já a velocidade foi mantida constante e igual a $20 \mathrm{~cm} / \mathrm{s}$, uma vez que sua variação apresentou pouca influência nas características das gotas aspergidas, como volume e forma.

O princípio de funcionamento do SiEO está vinculado às propriedades físicas do material líquido utilizado para impressão, por exemplo, à sua tensão superficial. ${ }^{(10)}$ Baseado nesta afirmação, os valores de tensão superficial e massa específica dos Fotoresistes AZ-2400 e AZ-I I IS foram medidos por meio de técnicas específicas utilizando um tensiômetro e um picnômetro, respectivamente. Esses valores são apresentados na Tabela 2 , na qual o Fotoresiste AZ-2400 apresenta valores superiores ao AZ-I I IS para as duas propriedades.

Tabela I. Distância (d), velocidade (v) e pressão $(P)$ utilizados, como elementos de controle na deposição das soluções dos Fotoresistes AZ-2400 e AZ-IIIS, após método RCA de limpeza de substrato, cujos resultados de aplicação podem ser observados na Figura

\begin{tabular}{ll}
\hline $\begin{array}{c}\text { Parâmetros } \\
\text { de controle }\end{array}$ & \multicolumn{1}{c}{$\begin{array}{c}\text { Sistema } \\
\text { controlado }\end{array}$} \\
\hline Distancia "d" & $\mathrm{d}_{1}=5,0 \mathrm{~cm} ; \mathrm{d}_{2}=3,0 \mathrm{~cm} ; \mathrm{d}_{3} \mathrm{ed}_{4}=\mathrm{I}, 5 \mathrm{~cm}$ \\
Velocidade "v" & $20 \mathrm{~cm} / \mathrm{s}$ \\
Pressão "P" & $\mathrm{P}_{1}=7,5 \mathrm{~cm} \mathrm{de} \mathrm{H}_{2} \mathrm{O}$ \\
& $\mathrm{P}_{2}=1,0 \mathrm{bar}$ \\
\hline
\end{tabular}

Tabela 2. Caracterização das soluções de polímero Fotoresiste AZ-2400 e AZ-I I IS quanto à sua tensão superficial e massa específica

\begin{tabular}{ccc}
\hline Polímero & Tensão superficial & Massa específica \\
\hline AZ-2400 & 32 dyn/cm $\left(\right.$ dina.. $\left.\mathrm{cm}^{-1}\right)$ & $1,03 \mathrm{~g} / \mathrm{mL}$ \\
AZ-I I IS & $30 \mathrm{dyn} / \mathrm{cm}\left(\right.$ dina.. $\left.\mathrm{cm}^{-1}\right)$ & $1,00 \mathrm{~g} / \mathrm{mL}$ \\
\hline
\end{tabular}

\section{RESULTADOS}

A Figura 6 mostra resultados da deposição de tinta azul sobre substratos (folhas) de papel (Figura 6a) e poliestireno comercial (Figura 6b) cujos parâmetros de deposição foram detalhados no item 2. O objetivo destas fotos é verificar a influência das características do substrato na formação do material impresso, bem como confirmar a utilização desse equipamento na fabricação de filmes. Observa-se que a tinta, quando depositada em papel (Figura 6a), apresenta característica irregular se comparada à forma circular obtida quando depositada sobre poliestireno transparente (Figura 6b). Essa característica deve estar associada à absorção da tinta pelo papel, que modifica a forma do filme obtido. Conclui-se, portanto, que a superfície do poliestireno possui característica mais hidrofóbica, o que contribui para a formação de discos (ou gotas) mais definidos cuja área varia de $440 \mu \mathrm{m}$ a $780 \mu \mathrm{m}$. Tal variação deve estar relacionada à diferença de tamanho observada entre os diâmetros dos furos micro-puncionados da válvula ejetora (Figura 2).

A Figura 7 apresenta a microscopia da deposição da solução de Pedot sobre substrato de papel. As imagens foram obtidas iluminando-se o sistema papel+Pedot com luz azul, para melhorar o contraste das figuras. Nestas fotos fica clara a possibilidade de deposição de materiais poliméricos via sistema de injeção eletrônica, mas demonstrando a característica (forma) irregular do Pedot depositado sobre papel.

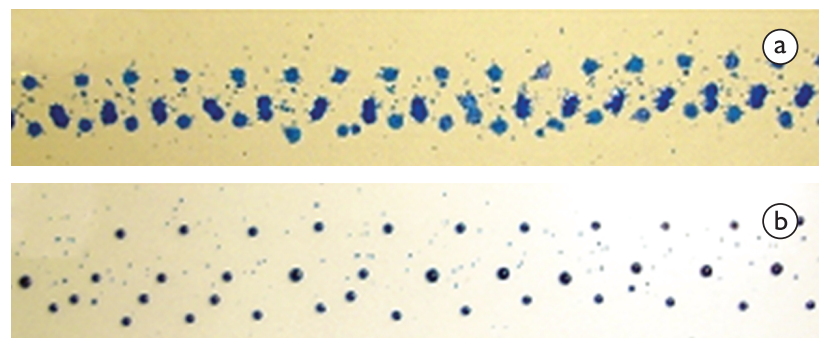

Figura 6. Fotografia da sequência de deposição de tinta azul cujos parâmetros utilizados estão disponíveis no item 2. Substratos de: a) papel; e b) poliestireno. 

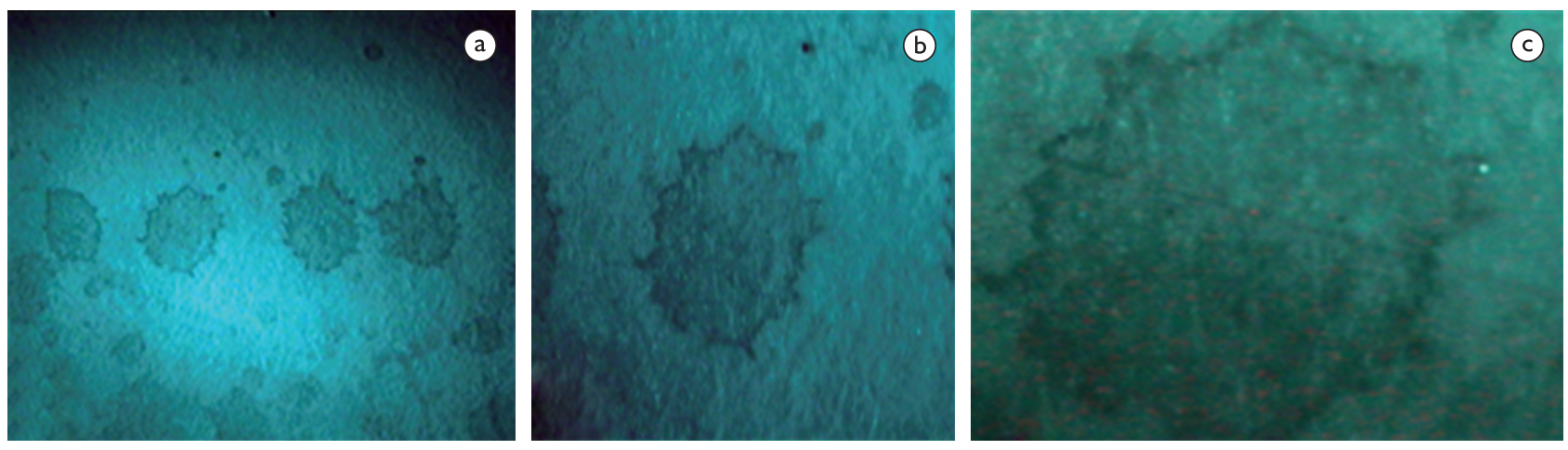

Figura 7. Sequências de gotas à base de Pedot depositadas sobre o papel com ampliações de: a) I0X; b) 25X; e c) 50X. Microscopia com redução de $7 X$.

Para caracterizar as grandezas das gotas aspergidas de Fotoresiste em relação à sua forma e volume, foram utilizados diferentes parâmetros nos ensaios, tais como, distância de aspersão, pressão aplicada e tratamento do substrato. É importante destacar que parâmetros como distância do substrato à válvula injetora e velocidade de movimentação do substrato influenciam diretamente na distância entre os círculos do material depositado, mas, praticamente, não influenciam na área desses círculos.

A Figura 8 mostra os gráficos resultantes de ensaios com os Fotoresistes AZ-2400 e AZ-I I IS. Nesse contexto, os primeiros ensaios foram realizados em substratos in natura, ou seja, tal como recebidos pelo fornecedor. As gotas ejetadas apresentaram diâmetro de, aproximadamente, $500 \mu \mathrm{m}$ e $1.700 \mu \mathrm{m}$, respectivamente (Figura 8a). O comportamento do Fotoresiste AZ-2400, após tratamento pelo método de limpeza RCA, também pode ser observado na Figura 8a, onde o diâmetro médio resultante foi de $2.000 \mu \mathrm{m}$. A Figura $8 \mathrm{~b}$ apresenta graficamente os diâmetros resultantes das gotas depositadas em diferentes valores de distância de aspersão. As três primeiras colunas mostram uma pequena diferença na variação dos diâmetros médios. Já a quarta coluna apresenta um aumento considerável no diâmetro médio em relação às três primeiras, de aproximadamente $64 \%$, possivelmente devido à pressão inicial aplicada. Os ensaios foram realizados com Fotoresiste AZ- I I IS em substratos preparados com o método de limpeza RCA e posteriormente expostos à luz Ultra Violeta.

\section{DISCUSSÃO}

Neste trabalho foram apresentados os resultados obtidos pela utilização de um equipamento desenvolvido a partir da tecnologia automotiva de injeção eletrônica para fabricação de filmes finos de polímeros eletrônicos. O equipamento mostra-se aplicável para esse tipo de

(a)

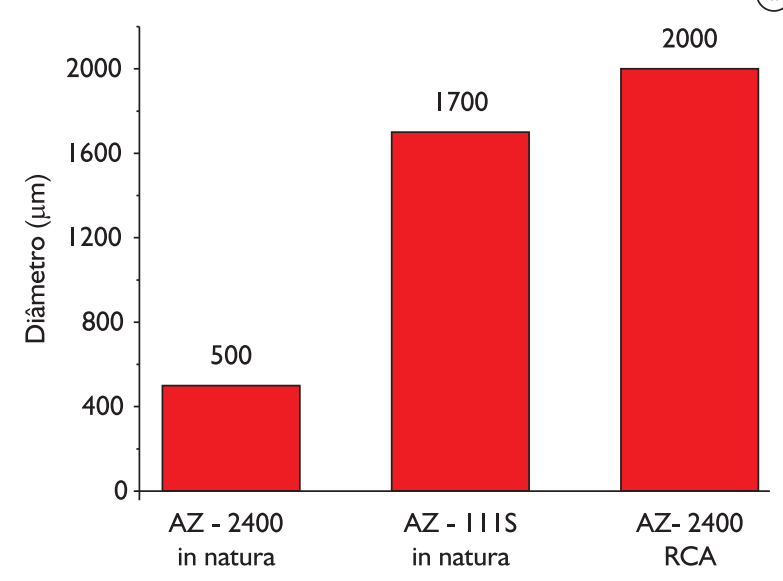

Fotoresistes AZ-2400 e AZ- I I IS

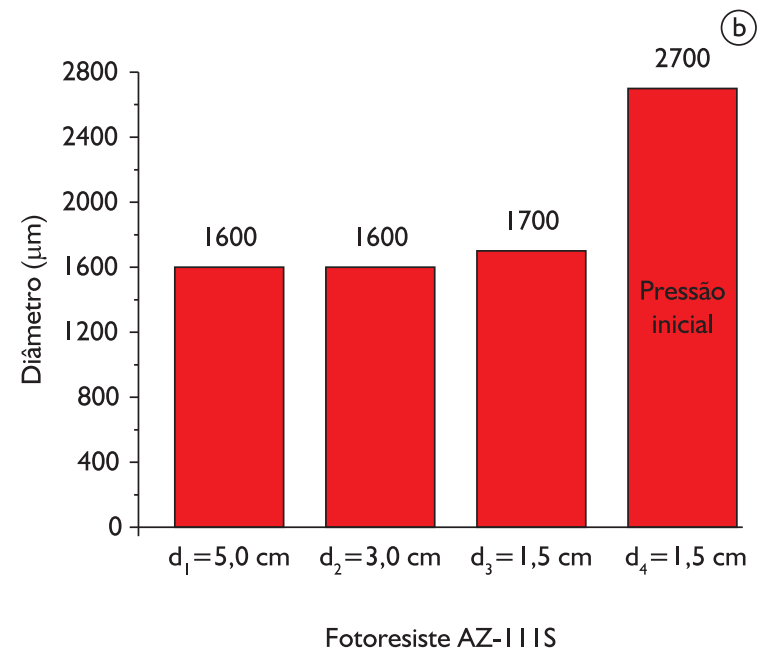

Figura 8. Gráfico resultante de ensaios com os polímeros AZ-2400 e AZ-I I IS. Valores obtidos utilizando diferentes parâmetros: a) Variação apenas no tratamento do substrato; e b) parâmetros como "d" e "P" foram variados no ensaio com Fotoresiste AZ-I I IS, após método RCA de limpeza. 
impressão por suportar as características agressivas dos solventes existentes nas soluções poliméricas, sem alterar as propriedades físicas e químicas desses polímeros. $\bigcirc$ controle desenvolvido para a máquina possibilita a deposição desses filmes, bem como a análise da aplicação dos parâmetros usados.

A Tabela 3 mostra o quadro comparativo entre a técnica da IJT de deposição de polímeros usualmente empregadas na fabricação de dispositivos eletrônicos poliméricos e a técnica de deposição SiEO proposta neste trabalho. Observa-se que a técnica SiEO apresenta como principais vantagens o baixo custo de fabricação e a alta resistência química, que são características importantes para o desenvolvimento e a fabricação de dispositivos poliméricos comerciais, bem como baixo desperdício de material e alta seletividade.

Tabela 3. Tabela comparativa entre as técnicas de deposição polimérica das IJTs e do SiEO

\begin{tabular}{ccccc}
\hline Técnicas & $\begin{array}{c}\text { Custo de } \\
\text { fabricação }\end{array}$ & Desperdício & Seletividade & $\begin{array}{c}\text { Resistência } \\
\text { Química }\end{array}$ \\
\hline SiEO & Baixo & Baixo & Alta & Alta \\
IJT & Alto & Baixo & Alta & Baixa \\
\hline
\end{tabular}

É importante salientar a diferença de tamanho das gotas depositadas nos substratos. Nos ensaios de deposição realizados nas laminas in natura, as amostras de AZ-2400 apresentam geometrias mais bem definidas e gotas com diâmetros, aproximados, quatro vezes menores que as gotas ejetadas sobre as lâminas preparadas com - método de limpeza RCA para o mesmo polímero. Isto leva, de antemão, a entender que o tratamento do substrato é um dos parâmetros que pode definir as características da solução aspergida. As amostras de Fotoresiste AZ-2400 e AZ-I I IS, após ensaios em lâminas in natura, mostram também uma grande diferença no diâmetro das gotas, sendo o primeiro de, aproximadamente, $500 \mu \mathrm{m}$ e o segundo, de I.700 $\mu \mathrm{m}$, respectivamente. Estes dados podem ser analisados a partir dos resultados apresentados na Tabela I. Nesse sentido, a tensão superficial e a massa específica do polímero AZ-2400 apresentam valores superiores ao AZ-I I IS, o que pode explicar seu comportamento hidrofóbico em relação ao segundo. Os ensaios realizados com AZ-I I IS, em substratos preparados com o método de limpeza RCA, e posteriormente expostos à luz UV, apresentam maiores diâmetros das gotas. A diferença quanto ao tamanho das gotas depositadas chega a valores de até $1.000 \mu \mathrm{m}$ : por exemplo, gotas com diâmetro aproximado de $2.700 \mu \mathrm{m}$ e $1.700 \mu \mathrm{m}$. Pouca influência é observada com a variação da distância entre a saída da válvula injetora e o substrato. Porém, nota-se uma diferença significativa quando se varia a pressão inicial aplicada ao sistema, ou seja, o volume de material aumenta, bem como o diâmetro das gotas aspergidas.

\section{CONCLUSÃO}

Os resultados obtidos ao longo do desenvolvimento deste trabalho mostram, pela primeira vez, a viabilidade técnica de produzir filmes orgânicos usados em microeletrônica (Fotoresistes) e em eletrônica orgânica (Pedot), a partir de um novo equipamento de impressão, cuja tecnologia é baseada em sistemas de injeção eletrônica automotiva. Devido ao custo elevado para impressão de filmes poliméricos, via equipamentos comerciais, pode-se afirmar que este equipamento mostra-se eficiente quanto às resistências químicas de impressão e quanto ao seu valor agregado. Destaca-se, portanto, que o protótipo proposto apresenta potencial para desenvolvimento de equipamentos mais robustos e funcionais para impressão de materiais orgânicos. Neste sentido, a proposta de uso do SiEO é inédito e surge neste trabalho como uma alternativa de processo de fabricação de filmes poliméricos a baixo custo e com precisão.

\section{Agradecimentos}

Os autores agradecem o apoio recebido das seguintes agências de fomento: CAPES, INEO/CNPq, CNPq, Fapitec/SE e Fapemig.

\section{REFERÊNCIAS}

I BRASIL. Ministério do Desenvolvimento, Indústria e Comércio Exterior. Diretrizes da Política Industrial, Tecnológica e de Comércio Exterior (PITCE). 2003. Disponível em: <http://www.desenvolvimento.gov.br/sitio/ascom/ascom/ polindteccomexterior.php> Acesso em: 18 ago. 2010.

2 SWART, J. W.; VAN NOIJE, W. A política industrial e tecnológica de semicondutores. São Paulo: Sociedade Brasileira de Microeletrônica. Disponível em: <http://www.sbmicro.org.br/index.php?option=content\&task=view\&id=76> Acesso em: 26 fev. 2010.

3 CRUZ, C. H. B. A universidade, a empresa e a pesquisa que o país precisa. Parcerias estratégicas. Disponível em: <http://www.cgee.org.br/parcerias/p08.php> Acesso em: 30 nov. 2009. 
4 FUJIFILM DIMATIX INC. Dimatix materials printer DMP-5000. Disponível em: <http://www.dimatix.com/divisions/ materials-deposition-division/materials-printer-dmp-5000.asp> Acesso em: 3 dez. 2010.

5 ULVAC TECHNOLOGIES, INC. Precision inkjet printer. Disponível em: <http://www.ulvac.com/flatpanel/litrexseries.asp >. Acesso em: 20 set. 2010.

6 HERZER, N. et al. Fabrication of Pedot-OTS-patterned ITO substrates. Journal of Materials Chemistry, v. 20, n. 32, p. 66I8-2I, 2010.

7 GONÇALVES, P. M. F. Concepção de um motor de combustão interna para um veículo automóvel de extra-baixo consumo de combustível. 2008. I 9 f. Dissertação (Mestrado em Engenharia Mecânica) - Faculdade de Ciências e Tecnologia da Universidade de Coimbra, Coimbra, 2008.

8 CRUZ, T. et al. Processos de fabricação veicular. São Bernando do Campo: Bosch, 2009.

9 KERN, W. Purifying Si and SiO2 surfaces with hydrogen peroxide. Semiconductor International, v. 7, p. 94-9, Apr. 1984.

I0 SANTOS, A. F. F. Estudo da tecnologia de impressão por jato de tinta para a deposição de filmes finos poliméricos. 2005. 95 f. Dissertação (Mestrado em Engenharia de Sistemas Eletrônicos) - Engenharia Elétrica da Universidade de São Paulo, São Paulo, 2005.

Recebido em: 08/II/2010

Aceito em: $31 / 03 / 201 \mathrm{I}$ 